\title{
EVALUASI KETEPATAN KODE DIAGNOSIS PENYEBAB DASAR KEMATIAN BERDASARKAN ICD-10 DI RS PANTI RAPIH YOGYAKARTA
}

\author{
Nuryati ${ }^{1}$; Trian Hidayat ${ }^{2}$ \\ Rekam Medis Sekolah Vokasi Universitas Gadjah Mada \\ nur3yati@yahoo.com; trianespapat@gmail.com
}

\begin{abstract}
ABSTRAK
Latar belakang: Penentuan kode sebab dasar kematian sangat penting dilaksanakan secara tepat agar laporan mortalitas dan tindakan pencegahan penyakit mematikan dapat terlaksana secara optimal. Penentuan kode diagnosis penyebab dasar kematian sangat ditentukan oleh keahlian staff coding dalam mengkode dan kepatuhan dokter dalam mengisi sebab kematian sesuai aturan. Aturan yang digunakan untuk menentukan kode diagnosis penyebab dasar kematian adalah berdasarkan ICD-10 dengan dibantu Buku Pedoman Penentuan Kode Penyebab Kematian Menurut ICD-10 serta tabel bantu berupa tabel MMDS.

Tujuan: Mengetahui pelaksanaan penentuan kode diagnosis penyebab dasar kematian di RS Panti Rapih Yogyakarta, persentase ketepatan hasil kode diagnosis penyebab dasar kematian, dan faktor-faktor yang menyebabkan ketidaktepatan kode sebab dasar kematian.

Metode: Penelitian ini menggunakan metode penelitian deskriptif dengan pendekatan kualitatif dan rancangan penelitian fenomenology. Subjek pada penelitian ini adalah staff coding, dokter, dan Kepala Instalasi Rekam Medis, sedangkan objek penelitian ini adalah Laporan Registrasi Kematian RS Panti Rapih Yogyakarta tahun 2012. Teknik pengumpulan data dengan observasi, wawancara, dan studi dokumentasi.

Hasil: Pelaksanaan pengkodean sebab dasar kematian di RS Panti Rapih Yogyakarta belum sepenuhnya sesuai dengan ICD-10, staff coding sebab kematian hanya mengkode diagnosis yang sudah dituliskan oleh dokter. Urutan penyakit menuju kematian yang tepat memiliki persentase sebesar $69,59 \%$ dengan $U C o D$ yang tepat sebesar $97,48 \%$ dan $U C o D$ yang tidak tepat $2,52 \%$, sedangkan urutan penyakit menuju kematian yang tidak tepat sebesar $30,41 \%$ dengan $U C o D$ yang tepat sebesar $38,46 \%$ dan $U C o D$ yang tidak tepat $61,54 \%$. Total prosenstase ketepatan $U C o D$ sebesar $79,53 \%$ dan yang tidak tepat sebesar 20, 47\%. Faktor-faktor yang menyebabkan ketidaktepatan kode sebab dasar kematian adalah tidak adanya SPO tentang pengkodean sebab dasar kematian, belum digunakannya tabel MMDS sebagai milik rumah sakit yang dijadikan fasilitas untuk staff coding, tidak semua dokter mengisi diagnosis sebab dasar kematian, dan tidak adanya audit coding atau evaluasi ketepatan kode sebab dasar kematian.
\end{abstract}

Kata kunci: Penilaian Teknologi, Teknometrik, SMART, SIMRS Rawat Inap

\section{PENDAHULUAN}

Rumah sakit adalah institusi yang menyediakan tempat tidur rawat inap, pelayanan medis, dan pelayanan keperawatan terus-menerus untuk diagnosis dan pengobatan oleh staf medis yang terorganisir (Huffman,1994). Fungsi rumah sakit adalah sebagai penyelenggaraan pelayanan pengobatan dan pemulihan kesehatan sesuai dengan standar pelayanan rumah sakit, pemeliharaan dan peningkatan kesehatan perorangan melalui pelayanan kesehatan yang paripurna tingkat kedua dan ketiga sesuai kebutuhan medis, penyelenggaraan pendidikan dan pelatihan sumber daya manusia dalam rangka peningkatan kemampuan dalam pemberian pelayanan kesehatan, dan penyelenggaraan penelitian dan pengembangan serta penapisan teknologi bidang kesehatan dalam rangka peningkatan pelayanan kesehatan dengan memperhatikan etika ilmu pengetahuan bidang kesehatan (UU No 44 tahun 2009 pasal 5).

Setiap rumah sakit diwajibkan menyelenggarakan rekaman atau catatan dari segala pelayanan yang diberikan kepada pasien yang disebut rekam medis. Menurut Huffman (1994), rekam medis adalah rekaman atau catatan mengenai siapa, apa, mengapa, bilamana, dan bagaimana pelayanan yang diberikan 
kepada pasien selama masa perawatan, yang memuat pengetahuan mengenai pasien dan pelayanan yang diperoleh serta memuat informasi yang cukup untuk mengidentifikasi pasien, membenarkan diagnosis dan pengobatan serta merekam hasilnya. Berkas rekam medis sangat menentukan terciptanya laporan kesehatan yang valid, untuk itu proses penulisan, pengolahan, dan pelaporan rekam medis harus terjaga kualitasnya. Dengan demikian perekam medis memegang peranan penting sebagai pengumpul, pengolah, dan penyaji informasi kesehatan. Salah satu informasi kesehatan yang tidak kalah penting adalah diagnosis penyebab dasar kematian, diagnosis ini nantinya digunakan sebagai underlying cause of death (UCoD) pada surat keterangan kematian dan juga sebagai laporan mortalitas. Dalam hal ini peran staff coding dan dokter sangat diperlukan, diagnosis penyebab dasar kematian yang dituliskan oleh dokter menempati peranan vital sebagai bahan penegakan diagnosis penyebab dasar kematian yang akan diolah oleh staff coding. Untuk itu dokter dan staff coding harus menunaikan tugasnya sesuai aturan. Menurut WHO aturan untuk penegakan diagnosis penyebab kematian adalah berdasarkan ICD-10 dilengkapi dengan Buku Panduan Penentuan Kode Penyebab Kematian Menurut ICD-10 serta Tabel MMDS sebagai alat crosscheck.

Menurut Depkes RI (2008), data penyebab kematian yang disusun berdasarkan ICD-10 merupakan sumber data yang dapat dipakai untuk menghitung angka harapan hidup, angka kematian menurut penyebab dan umur. Selain itu data penyebab dasar kematian dapat dijadikan sebagai bahan pertimbangan untuk mengambil keputusan terkait dengan upaya pencegahan dari penyakit atau kasus yang mematikan (preventif primer) sehingga status kesehatan masyarakat menjadi lebih baik. Misalnya ketika penyakit demam berdarah (dengue hemorrhage fever) menjadi salah satu 10 besar penyebab dasar kematian maka dapat dijadikan sebagai salah satu pertimbangan untuk dilakukannya penyuluhan menutup, menguras, dan mengubur (3M) dan pengasapan serta sosialisasi tentang bahaya nyamuk demam berdarah. Selain itu dapat juga digunakan untuk mengambil keputusan terkait keselamatan dalam berkendara ketika ditemukan kasus kecelakaan lalu lintas sebagai salah satu dari 10 besar penyebab dasar kematian, salah satu upaya pencegahannya adalah dengan menyalakan lampu kendaraan baik siang maupun malam. Menurut Depkes RI (2008), sampai saat ini, pencatatan dan pelaporan data kematian masih jauh dari memadai dan belum seluruhnya terstandar menurut ICD-10.
Menurut WHO dalam Depkes RI (2008), penyebab dasar kematian adalah penyakit/kondisi yang merupakan awal dimulainya rangkaian perjalanan penyakit menuju kematian atau keadaan kecelakaan atau kekerasan yang menyebabkan cedera dan berakhir dengan kematian. Definisi ini bertujuan untuk menganjurkan agar seluruh informasi yang relevan dicatat. Dalam definisi tidak dicantumkan gejala kematian seperti heart failure atau respiratory failure (ICD-10 volume 2). Sebab utama kematian adalah:

a. Penyakit/cidera yang menimbulkan serangkaian kejadian yang berakhir dengan kematian, atau

b. Kecelakaan atau kekerasan yang menimbulkan cidera yang mematikan.

Penentuan diagnosis dan kode penyebab kematian haruslah tepat dan akurat sesuai dengan aturan (ICD-10), guna memberikan penyediaan layanan kesehatan dan kemampuan untuk mengukur hasil pemeriksaan klinis dan finansial yang tepat yang dapat digunakan sebagai informasi yang dibutuhkan untuk meningkatkan kualitas pelayanan, perencanaan strategis, analisis keluaran, penelitian, analisis statistik dan keuangan serta dalam proses pengambilan keputusan (Skurka, 2003).

Dalam penentuan penyebab dasar kematian dapat digunakan tabel MMDS (Medical Mortality Data System). MMDS Decision Table dipakai untuk membantu penetapan UCoD (Underlying cause of death) yang benar dan penentuan kode penyebab multipel yang tepat. Decision table ini adalah kumpulan daftar yang memberikan panduan dan arah dalam penerapan rule seleksi dan modifikasi yang dipublikasikan dalam ICD-10 volume 2. Meskipun aslinya dirancang untuk pemakaian perangkat lunak otomatis yang ada di NCHS Amerika Serikat, tabel-tabel ini sangat bermanfaat untuk membantu petugas coding dengan ketetapan mengenai urutan yang bisa dan tidak bisa dipakai (Depkes RI, 2008).

Tujuan dari penelitian ini adalah untuk mengetahui pelaksanaan penentuan kode diagnosis penyebab dasar kematian di RS Panti Rapih Yogyakarta, persentase ketepatan hasil kode diagnosis penyebab dasar kematian, dan faktor-faktor yang menyebabkan ketidaktepatan kode sebab dasar kematian.

Penelitian yang telah dilakukan di RS Panti Rapih menggunakan jenis penelitian deskriptif dengan pendekatan kualitatif. Menurut Notoatmodjo (2010), penelitian deskriptif adalah penelitian yang dilakukan dengan tujuan utama membuat 
gambaran atau deskripsi tentang suatu keadaan secara objektif. Penelitian kualitatif adalah penelitian yang bermaksud untuk memahami fenomena tentang apa yang dialami oleh subjek penelitian misalnya perilaku, persepsi, motivasi, tindakan, dan lain-lain secara holistik dengan cara deskripsi dalam bentuk kata-kata dan bahasa, pada suatu konteks khusus yang alamiah dan dengan memanfaatkan berbagai metode ilmiah (Moloeng, 2004). Rancangan penelitian yang digunakan adalah penelitian fenomenologi, yaitu suatu penelitian untuk menunjuk pada pengalaman subjektif dari berbagai jenis dan tipe subjek yang ditemui atau penelitian yang terdisiplin tentang kesadaran dari perspektif pertama seseorang (Moloeng, 2004).

Subyek pada penelitian ini adalah staff coding sebab kematian, salah satu staff coding bagian olah data, salah satu dokter IGD, dan Kepala Instalasi Rekam Medis RS Panti Rapih Yogyakarta, sedangkan objek penelitian ini adalah Laporan Registrasi Kematian RS Panti Rapih Yogyakarta tahun 2012. Teknik pengumpulan data dengan observasi, wawancara, dan studi dokumentasi.

\section{PEMBAHASAN}

\section{Pelaksanaan Pengkodean Diagnosis Penye- bab Dasar Kematian}

Pelaksanaan pengkodean penyakit secara umum dilakukan oleh petugas olah data RS Panti Rapih Yogyakarta. Semua penyakit dikode oleh petugas tersebut, termasuk diagnosis kematian, namun tidak semua diagnosis kematian terisi seluruhnya. Jika demikian, petugas olah data akan meloloskan pengkodean tersebut, artinya tidak dilakukan pengkodean sama sekali. Khusus untuk pasien meninggal yang berdomisili dalam Kota Yogyakarta, pengkodean sebab kematiannya akan dilaksanakan oleh staff coding yang telah mengikuti pelatihan penentuan sebab kematian, untuk dilakukan proses reseleksi. Staff coding tersebut sekaligus sebagai petugas yang bertanggung jawab dalam penentuan kode sebab dasar kematian.

Pelaksanaan pengkodean diagnosis penyebab dasar kematian di RS Panti Rapih Yogyakarta hanya dilakukan pada pasien dalam Kota Yogyakarta, terkait dengan sampel proyek Departemen Kesehatan Republik Indonesia tentang penentuan sebab kematian di Indonesia.
Untuk pelaksanaannya, staff coding hanya mengkode diagnosis yang sudah dituliskan oleh dokter sesuai ICD-10 volume 1 dan 3 tanpa melakukan pengecekan kembali rule yang ada dalam ICD-10 volume 2 dan belum menggunakan tabel MMDS sebagai alat untuk crosscheck.

Terkait dengan penentuan kode sebab kematian bayi (usia kurang dari 7 hari) juga dilaksanakan apa adanya sesuai yang dituliskan oleh dokter, dengan demikian apabila dokter menuliskan diagnosis menuju kematian dan menentukan penyebab dasar kematiannya belum sesuai dengan ICD-10 maka kode juga mengikuti sehingga masih ditemukan penentuan kode diagnosis sebab kematian yang belum sesuai dengan aturan di ICD-10. Jika dokter tidak mengisi diagnosis penyebab kematiannya maka staff coding akan memintakan kelengkapannya ke dokter yang merawat. Jika dokter yang merawat tidak bisa melengkapi diagnosis penyebab kematiannya maka diagnosis penyebab kematian tersebut akan ditentukan oleh dokter yang telah diberi tanggung jawab untuk menentukan sebab dasar kematian dan sudah mengikuti pelatihan tentang pedoman pengisian formulir keterangan penyebab kematian.

Berdasarkan hasil observasi di Instalasi Rekam Medis RS Panti Rapih Yogyakarta sudah memiliki Standar Prosedur Operasional tentang pengkodean dan indeksing dengan nomor dokumen RSPR/5SP2/SPO.24, namun SPO yang mengatur cara penentuan kode sebab dasar kematian belum diuraikan secara spesifik, yang ada hanya SPO tentang pengkodean secara umum. Selain itu juga sudah terdapat diagnosis menuju kematian yang diisi dengan jelas oleh dokter. Terkait dengan kegiatan reseleksi diagnosis penyebab kematian sudah dilakukan oleh dokter yang merawat atau dokter yang bertanggung jawab, namun belum semuanya sesuai dengan kaidah penentuan diagnosis penyebab dasar kematian berdasarkan ICD-10. Diagnosis penyebab dasar kematian (UCoD) juga sudah tercantum dalam berkas rekam medis yang terlampir dalam Formulir Keterangan Penyebab Kematian.

Berdasarkan Depkes RI (2008), World Health Organization (WHO) telah menetapkan suatu himpunan prosedur atau rule yang harus diikuti untuk pemberian kode penyebab dasar 
kematian. Jika hanya satu penyebab kematian yang dilaporkan maka penyebab tersebut adalah UCoD dan digunakan untuk tabulasi. Jika lebih dari satu penyebab kematian yang dilaporkan, maka langkah pertama untuk memilih penyebab dasar kematian adalah dengan menetukan penyebab awal yang tepat yang mendahuluinya pada baris terbawah di bagian I dari surat keterangan kematian dengan menerapkan Prinsip umum atau Rule 1, 2, dan 3.

Penentuan kode sebab dasar kematian di RS Panti Rapih Yogyakarta belum menerapkan prinsip umum atau rule 1, 2, dan 3 sesuai Buku Panduan Penentuan Kode Penyebab Kematian Menurut ICD-10. Pelaksanaan penentuan kode sebab dasar kematian hanya berdasarkan diagnosis yang sudah ditentukan oleh dokter, staff coding hanya mengkode diagnosis yang dituliskan dokter tanpa mengecek kembali aturan tentang prinsip umum atau rule 1, 2, dan 3. Padahal pengecekkan kembali hasil penentuan sebab dasar kematian dengan rule penentuan sebab dasar kematian sesuai dengan ICD-10 penting dilakukan, tabel MMDS juga dapat dijadikan alat sebagai pedoman bantuan penentuan hubungan kausal dari penyakit menuju kematian. Jika ditemukan sebab dasar kematian yang kurang sesuai dengan ICD-10 maka staff coding bertanggung jawab untuk melakukan komunikasi dengan dokter yang bertanggung jawab agar dapat ditentukan kembali sebab dasar kematiannya yang tepat.

Menurut Hatta (2008), standar dan etik pengkodean (coding) yang dikembangkan AHIMA, meliputi beberapa standar yang harus dipenuhi oleh seorang pengkode (coder) profesional, antara lain: a. Akurat, komplet, dan konsisten untuk menghasilkan data yang berkualitas; b. Pengkode harus mengikuti sistem klasifikasi yang sedang berlaku dengan memilih pengkodean diagnosis dan tindakan yang tepat; c. Pengkodean harus ditandai dengan laporan kode yang jelas dan konsisten pada dokumentasi dokter dalam rekam medis pasien; d. Pengkode profesional harus berkonsultasi dengan dokter untuk klarifikasi dan kelengkapan pengisian data diagnosis dan tindakan; e. Pengkode profesional tidak mengganti kode pada bill pembayaran; f. Pengkode profesional harus sebagai anggota dari tim kesehatan, harus membantu dan menyosialisasikan kepada dokter dan tenaga kesehatan lain; g. Pengkode profesional harus mengembangkan kebijakan pengkodean di institusinya; h. Pengkode profesional harus secara rutin meningkatkan kemampuannya di bidang pengkodean; i. Pengkode profesional senantiasa berusaha untuk memberi kode yang paling sesuai untuk pembayaran

Menurut Badan Penelitian dan Pengembangan Kesehatan Kementrian Kesehatan RI (2010), penyebab kematian adalah semua penyakit, kondisi atau penyebab cedera yang menyebabkan atau berperan terhadap terjadinya kematian. Dalam definisi ini tidak termasuk gejala dan cara kematian seperti henti jantung atau henti napas. Oleh karena cara kematian henti jantung dan henti napas tidak memberikan informasi yang baik dan tepat bagi pengelola program kesehatan maka hal ini sebaiknya dihindarkan.

Menurut penelitian Jemal, dkk (2005), Statistik penyebab kematian di Amerika Serikat didasarkan pada penyebab dasar kematian. Penyebab dasar kematian didefinisikan sebagai penyakit atau luka yang memprakarsai urutan kejadian yang mengarah langsung ke kematian. Hal ini dipilih dari kondisi masuk dalam penyebab kematian bagian pada sertifikat kematian oleh dokter sertifikasi, koroner, atau pemeriksa medis berdasarkan urutan kejadian morbiditas dan aturan pengkodean yang ditetapkan oleh International Classification of Diseases (ICD). Artinya di negara lain yaitu Amerika Serikat, penentuan kode sebab dasar kematian juga harus didasarkan pada ICD-10 berdasarkan urutaan penyakit menuju kematian. Diagnosis penyebab kematian harus diisikan oleh dokter penanggung jawab.

Menurut penelitian Mathers, dkk (2005), Idealnya, sistem registrasi vital harus mencakup semua kematian yang terjadi pada populasi tertentu, harus tepat mencatat umur dan jenis kelamin dari masing-masing orang yang meninggal, dan penyebab kematian yang dilaporkan harus didasarkan pada pendapat staf medis yang berkompeten. Petugas yang terlatih diperlukan untuk memastikan bahwa informasi tentang kondisi medis yang menyebabkan kematian dikodekan tepat sehingga penyebab kematian dapat diidentifikasi. Untuk menghitung angka kematian usia tertentu, yang merupakan output yang paling berguna dari sistem registrasi vital untuk tujuan kebijakan, estimasi yang dapat dijadikan acuan penduduk mengenai risiko kematian. Diambil bersama- 
sama sumber daya yang diperlukan untuk membangun dan mempertahankan fungsi sistem registrasi vital, termasuk penggabungan revisi periodik dari ICD, cukup besar. Akibatnya, sistem registrasi vital yang baik umumnya lebih mungkin ditemukan di negara maju. Dari penelitian ini dapat diambil kesimpulan bahwa penentuan kode diagnosis penyebab kematian harus ditentukan oleh tenaga rekam medis yang sudah terlatih dan paham tentang penentuan diagnosis penyebab dasar kematian, jika penentuan diagnosis penyebab dasar kematian sudah ditentukan oleh dokter dan sesuai dengan kaidah penentuan diagnosis penyebab kematian dalam ICD-10 maka staff coding sebab kematian juga akan dengan tepat mengkode diagnosis penyebab dasar kematiannya, sehingga bukan hal yang mustahil sertifikat kematian yang baik juga dapat dihasilkan dari negara berkembang seperti Indonesia.

Berdasarkan dua penelitian di atas, pelaksanaan penentuan kode sebab dasar kematian di RS Panti Rapih Yogyakarta belum sepenuhnya sesuai dengan uraian tersebut. Staff coding sebab kematian memang sudah dibekali pelatihan penentuan kode sebab kematian, namun dalam praktiknya ilmu yang didapat belum bisa diterapkan dengan optimal, karena staff coding hanya mengkode diagnosis yang sudah dituliskan oleh dokter. Padahal tidak semua dokter memahami cara penentuan diagnosis penyebab dasar kematian berdasarkan ICD-10. Sehingga penentuan kode sebab dasar kematian di RS Panti Rapih Yogyakarta belum sepenuhnya tepat sesuai ICD-10.

Format penulisan penyebab kematian di RS Panti Rapih Yogyakarta sudah sesuai dengan anjuran dari ICD-10 dalam Badan Penelitian dan Pengembangan Kesehatan Kementrian Kesehatan RI (2010) yaitu meliputi bagian I dan bagian II. Bagian I terdiri dari a, b, c, dan d yang merupakan urutan penyakit menuju kematian, sedangkan bagian I merupakan penyakit lain yang tidak berkaitan dengan kematian namun turut menyertai dalam peristiwa kematian. Dalam pengisiannya, belum semua diagnosis diisikan secara tepat di bagian I dan II, belum semua diagnosis dituliskan berdasarkan penyakit menuju kematian sesuai ICD-10 dan penentuan $\mathrm{UCoD}$ juga belum sepenuhnya mengacu pada ICD-10.

Terkait dengan hubungan kausal juga belum sepenuhnya dilakukan secara tepat, karena belum menggunakan prinsip umum atau rule 1, 2, dan 3 serta belum menggunakan tabel MMDS untuk mengecek kembali hubungan kausal penyakit yang meyebabkan kematian.

Pelaksanaan kode sebab dasar kematian khusus untuk perinatal di RS Panti Rapih Yogyakarta sama halnya dengan pengkodean sebab dasar kematian usia di atas 7 hari, staff coding hanya mengkode diagnosis yang dituliskan oleh dokter saja tanpa mengecek kembali cara pengkodean sebab dasar kematian perinatal sesuai dengan ICD-10 dan Depkes RI (2008).

\section{Persentase Ketepatan Kode Diagnosis}

Penghitungan persentase ketepatan kode penyebab dasar kematian yang dilakukan peneliti adalah dengan melakukan studi dokumentasi terhadap Laporan Registrasi Kematian selama tahun 2012 yang berisi urutan penyakit menuju kematian dan final UCoD yang ditentukan, kedua item dalam dokumen ini kemudian dicocokkan dengan prinsip umum, rule 1 , rule 2 , dan rule 3 sesuai dengan ketentuan dari WHO dan ICD-10 sekaligus mengecek hubungan sebab kausal berdasarkan tabel MMDS. Berdasarkan hasil studi dokumentasi terhadap Laporan Registrasi Kematian RS Panti Rapih Yogyakarta tahun 2012 dapat diketahui bahwa sudah terdapat urutan penyakit menuju kematian namun belum semua urutan tersebut sesuai dengan hubungan kausal yang dijabarkan dalam tabel MMDS. Penulisan final UCoD juga sudah tercantum, namun belum semuanya sesuai dengan cara penentuan UCoD berdasarkan ICD-10.

Persentase analisis ketepatan kode penyebab dasar kematian berdasarkan ICD-10 di RS Panti Rapih Yogyakarta dapat diketahui bahwa, dari 171 data sebab kematian yang diteliti terdapat 119 atau $69,59 \%$ urutan penyakit menuju kematian yang sudah sesuai hubungan kasualnya dengan tabel MMDS dan 52 atau $30,41 \%$ urutan penyakit menuju kematian belum sesuai hubungan kausalnya dengan tabel MMDS.

Tabel 1 Rekapitulasi Urutan Penyakit Menuju Kematian

\begin{tabular}{|c|l|c|c|}
\hline No & \multicolumn{1}{|c|}{ Kriteria } & Jml & $\%$ \\
\hline 1 & $\begin{array}{l}\text { Urutan Penyakit Menuju } \\
\text { Kematian yang Tepat }\end{array}$ & 119 & 69,59 \\
\hline 2 & $\begin{array}{l}\text { Urutan Penyakit Menuju } \\
\text { Kematian yang Tidak Tepat }\end{array}$ & 52 & 30,41 \\
\hline
\end{tabular}


Dari 119 urutan penyakit menuju kematian yang hubungan kausalnya tepat, dapat diketahui bahwa 116 penentuan UCoD sudah tepat atau sebesar $97,48 \%$, dan 3 penentuan $\mathrm{UCoD}$ belum tepat atau sebesar 2,52\%. Hasil tersebut didapat dari perhitungan sebagai berikut dan ditampilkan dalam tabel 2 di bawah ini:

Tabel 2 Rekapitulasi UCoD dalam Urutan Penyakit Menuju Kematian

\begin{tabular}{|c|l|c|c|}
\hline No & \multicolumn{1}{|c|}{ UCoD } & Jml & \% \\
\hline 1 & Tepat & 116 & 97,48 \\
\hline 2 & Tidak Tepat & 3 & 2,52 \\
\hline
\end{tabular}

Dari 52 urutan penyakit menuju kematian yang belum tepat, dapat diketahui bahwa jumlah UCoD yang tepat adalah 20 atau $38,46 \%$ dan UCoD yang tidak tepat sebanyak 32 atau $61,54 \%$.

Tabel 3 Rekapitulasi UCoD dalam Urutan Penyakit Menuju Kematian yang Tidak Tepat

\begin{tabular}{|c|l|c|c|}
\hline No & \multicolumn{1}{|c|}{ UCoD } & Jml & \% \\
\hline 1 & Tepat & 20 & 38,46 \\
\hline 2 & Tidak Tepat & 32 & 61,54 \\
\hline
\end{tabular}

Dari data tersebut di atas, dapat diketahui bahwa total penentuan UCoD yang tepat adalah sebanyak 136 atau $79,53 \%$ dan total $\mathrm{UCoD}$ yang tidak tepat adalah sebanyak $35 \%$ atau $20,47 \%$.

Tabel 4 Rekapitulasi Total Ketepatan UCoD

\begin{tabular}{|c|l|c|c|}
\hline No & \multicolumn{1}{|c|}{ UCoD } & Jml & \% \\
\hline 1 & Tepat & 136 & 79,53 \\
\hline 2 & Tidak Tepat & 35 & 20,47 \\
\hline
\end{tabular}

Berdasarkan Depkes RI (1997), tenaga medis sebagai seorang pemberi kode bertanggung jawab atas keakuratan kode dari suatu diagnosis yang sudah ditetapkan oleh tenaga medis. Oleh karenanya untuk hal yang kurang jelas atau yang tidak lengkap, sebelum coding ditetapkan komunikasikan terlebih dahulu para dokter yang membuat diagnosis tersebut. Setiap pasien selesai mendapatkan pelayanan baik rawat jalan maupun rawat inap, maka dokter harus segera membuat diagnosis akhir. Kelancaran dan kelengkapan pengisian rekam medis di unit rawat jalan dan di ruang rawat inap atas kerja sama tenaga medis dan tenaga kesehatan lain yang ada di masing-masing unit kerja tersebut. Untuk lebih meningkatkan informasi dalam rekam medis, petugas rekam medis harus membuat koding sesuai dengan klasifikasi yang tepat.

Dari uraian di atas dapat diketahui bahwa pelaksanaan pengkodean diagnosis penyebab dasar kematian di RS Panti Rapih Yogyakarta belum sepenuhnya sesuai dengan teori di atas karena belum semua diagnosis penyebab dasar kematian dikode secara tepat sesuai dengan ICD-10. Pelaksanaan pengkodean diagnosis penyebab dasar kematian di RS Panti Rapih Yogyakarta hanya berdasarkan diagnosis yang dituliskan oleh dokter, padahal tidak semua dokter sudah sesuai ICD-10 dalam menentukan diagnosis penyebab dasar kematiannya. Selain itu, staff coding tidak mengecek kembali urutan penyakit menuju kematian dan penentuan penyebab dasar kematian dengan tabel MMDS dan rule yang ada di ICD-10. Jika dalam penulisan diagnosis penyebab dasar kematian, dokter belum sesuai dengan ICD-10 maka seharusnya staff coding sebagai pemberi kode wajib melakukan komunikasi dengan dokter agar memastikan kembali agar diagnosis penyebab dasar kematian adalah benar-benar yang tepat sesuai dengan ICD-10.

3. Faktor-Faktor Ketidaktepatan Kode Diagnosis Penyebab Dasar Kematian

Faktor-faktor yang menyebabkan ketidaktepatan kode diagnosis penyebab kematian dapat dilihat melalui unsur manajemen, menurut Emerson dalam Arifin (2012), manajemen mempunyai lima unsur (5M), yaitu man, money, material, machine, dan method.

Berdasarkan teori manajemen di atas, ketidaktepatan penentuan kode diagnosis penyebab kematian di RS Panti Rapih Yogyakarta dipengaruhi oleh man, machine, dan method.

a. Tidak Ada Uraian Tugas atau Standar Prosedur Operasional yang Mengatur

RS Panti Rapih Yogyakarta belum memiliki Standar Operasional Prosedur khusus penentuan kode sebab dasar kematian, jadi selama ini staff coding sebab kematian melakukan 
uraian tugas ini tanpa SPO dan tanpa aturan khusus, staff coding hanya mengkode diagnosis yang telah ditentukan oleh dokter dan hanya memenuhi kepentingan pelaporan sebab kematian ke dinas terkait. Berdasarkan teori Tambunan (2013) di atas, dapat disimpulkan bahwa kepastian semua keputusan dan tindakan terkait penentuan kode sebab dasar kematian serta penggunaan fasilitas yang dilakukan oleh staff coding di Instalasi Rekam Medis RS Panti Rapih Yogyakarta belum berjalan efektif, efisien, konsisten, terstandar, dan sistematis.

b. Fasilitas Terkait Pelaksanaan Kode Sebab Kematian Belum Lengkap

Di Intalasi Rekam Medis RS Panti Rapih Yogyakarta belum diberlakukan tabel MMDS dan belum diresmikan oleh pihak rumah sakit untuk dijadikan sebagai acuan pengkodean sebab dasar kematian, sehingga dalam pelaksanaan penentuan kode sebab dasar kematian belum dicek dengan tabel MMDS. Staff coding hanya mengkode diagnosis yang dituliskan oleh dokter tanpa mengecek hubungan kausal berdasarkan tabel MMDS dan belum menerapkan rule sesuai ICD-10.

c. Tidak Semua Dokter Mengisi Diagnosis Menuju Kematian

Pengisian diagnosis penyebab dasar kematian di RS Panti Rapih Yogyakarta sudah sesuai karena yang mengisi diagnosis adalah dokter, tetapi belum semua dokter (faktor manusia) menuliskan diagnosis penyebab kematiannya, atau urutan penulisan diagnosis penyebab kematiannya belum sesuai dengan ICD-10.

d. Tidak Adanya Audit Coding atau Evaluasi HasilPengkodean

Evaluasi yang belum dilakukan di RS Panti Rapih Yogyakarta adalah evaluasi kualitatif terkait dengan hasil penentuan kode sebab dasar kematian yang dibuat oleh staff coding. Dengan demikian tidak dapat diketahui kualitas dari hasil pengkodean sebab kematiannya, artinya ketepatan dan keakuratan kode sebab dasar kematian belum dapat diketahui karena belum pernah dilakukan audit coding atau evaluasi ketepatan kode sebab dasar kematian.

\section{KESIMPULAN}

a. Pelaksanaan penentuan kode sebab dasar kematian di RS Panti Rapih Yogyakarta hanya diberikan pada pasien dalam Kota Yogyakarta dan dilaksanakan tanpa SPO atau aturan tertentu dan belum sepenuhnya sesuai dengan ICD-10. Staff coding hanya mengkode diagnosis penyebab dasar kematian yang dituliskan oleh dokter tanpa menerapkan rule dalam ICD-10 dan belum mengecek kembali dengan tabel MMDS.

b. Analisis ketepatan kode sebab dasar kematian di RS Panti Rapih Yogyakarta diperoleh angka sebagai berikut, 119 atau 69,59\% pasien urutan penyakit menuju kematiannya sudah sesuai hubungan kausalnya dengan tabel MMDS dengan prosentase ketepatan UCoD sebesar $97,48 \%$ dan yang UCoD yang tidak tepat sebesar 2,52\%. 52 pasien atau 30,41\% urutan penyakit menuju kematiannya belum sesuai hubungan kausalnya dengan tabel MMDS dengan prosentase ketepatan UCoDnya sebesar $38,46 \%$ dan UCoD yang tidak tepat sebesar $61,54 \%$, sehingga prosentase total UCoD yang tepat sebesar $79,53 \%$ dan total UCoD yang tidak tepat sebesar $20,47 \%$.

c. Faktor-faktor yang menyebabkan ketidaktepatan kode sebab kematian adalah tidak adanya SPO atau aturan yang mengharuskan dilakukannya pengkodean sebab dasar kematian, belum dipakainya tabel MMDS sebagai fasilitas pengkodean, tidak semua dokter mengisi diagnosis penyebab kematian dan tidak adanya audit coding atau evaluasi ketepatan kode sebab dasar kematian.

\section{DAFTAR PUSTAKA}

Arifin, M. (2012). 5M Dalam Manajemen tersedia dalam: http://indonesianpublichealth. blogspot.com [Diakses 22 Mei 2013]

Badan Penelitian dan Pengembangan Kesehatan Kementrian Kesehatan RI. (2010). Pedoman Pengisian Formulir Keterangan Penyebab Kematian (FKPK) Panduan Untuk Dokter. Jakarta: Badan Penelitian Dan Pengembangan Kesehatan, Depkes RI. 
Nuryati, dkk. Evaluasi Ketepatan Kode Diagnosis Penyebab Dasar Kematian Berdasarkan ICD-10

Depkes RI. (1997). Pedoman Pengelolaan Rekam Medis Rumah Sakit Di Indonesia. Jakarta: Direktorat Jendral Pelayanan Medik.

Depkes RI. (2008). Buku Panduan Penentuan Kode Penyebab Kematian Menurut ICD-10. Jakarta: Badan Penelitian Dan Pengembangan Kesehatan, Depkes RI.

Hatta, G. R. (2008) Pedoman Manajemen Informasi Kesehatan di Sarana Pelayanan Kesehatan. Jakarta: UI Press.

Huffman, E.K. (1994). Health Information Management. Illinois: Physicians Record Company.

Jemal, A., Ward, E., Hao, Y. 2005. Trend In The Leading Causes Of Death In The United States, 1970-2002. Jurnal. Tersedia dalam www.jama.jamanetwork.com [Diakses tanggal 4 Juni 2013]
Mathers, C. D., Fat, M. D., Inoue, M., Rao, C., Lopez, A. D. 2005. Counting The Dead And What They Died From: An Assessment Of The Global Status Of Cause Of Death Data. Jurnal. Tersedia dalam www.scielosp.org [Diakses tanggal 4 juni 2013]

Undang-Undang Nomor 44 tahun 2009 tentang Rumah Sakit tersedia dalam www.hukor. depkes.go.id [Diakses tanggal 27 Mei 2013]

Tambunan, R. M. (2013). Pedoman Penyusunan Standard Operating Procedure (SOP). Jakarta: Maiestas Publishing 